\title{
Uncommon skeletal findings in systemic sclerosis
(scleroderma)
}

\section{Betsie van der Walt FCRad(D)}

\section{Irma van de Werke FRCR}

\section{Zarina Lockhat FFRad(D)SA}

Department of Radiology Kalafong Hospital, Pretoria

\section{Abstract}

Scleroderma or progressive systemic sclerosis is a diffuse disease characterised by excessive deposition of collagen and small-vessel arteritis. Systemic sclerosis is divided into two groups.

1. Diffuse scleroderma, where interstitial pulmonary fibrosis is common, and

2. The CREST syndrome, which is characterised more commonly by vasculitis with pulmonary hypertension.

The CREST syndrome consists of calcinosis of the skin, Raynaud's phenomenon, sclerodactyly, telangiectasis and oesophageal dysmotility.

This case describes a 48-year-old woman with known scleroderma demonstrating some of the less common radiological features.

\section{Case report}

A 48-year-old African woman with known scleroderma presented with difficulty in mastication, swallowing and laxity of the right temperomandibular joint. She was referred by the dermatologist for a skeletal survey and on the cervical spine $\mathrm{X}$-rays (Figs $\mathrm{la}+\mathrm{b}$ ) it was noted that the mandibular ramus was not clearly visualised; thus skull views were requested (Figs $2 \mathrm{a}+\mathrm{b}$ ). On these views the right ramus of the mandible was absent. This was then confirmed on the panorex view (Fig. 3), which

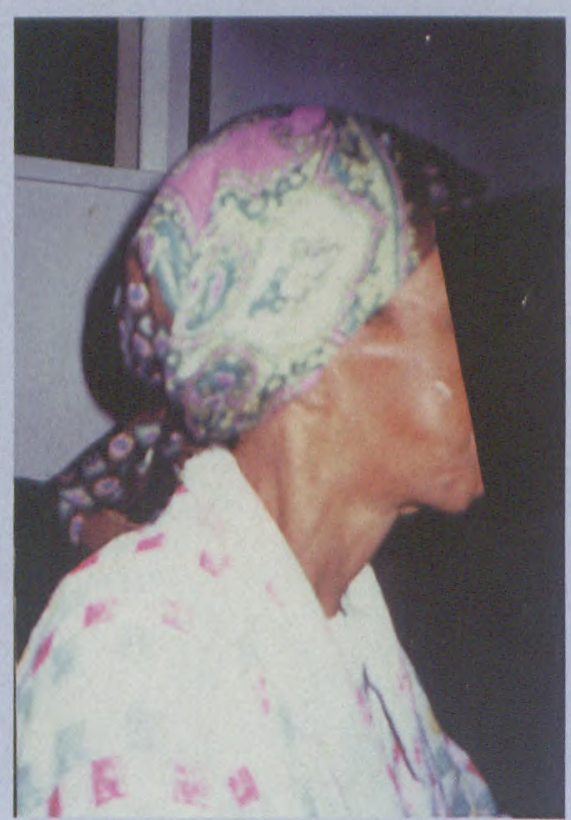

Fig. 1a. Lateral photograph of the patient's neck and mandibular region.

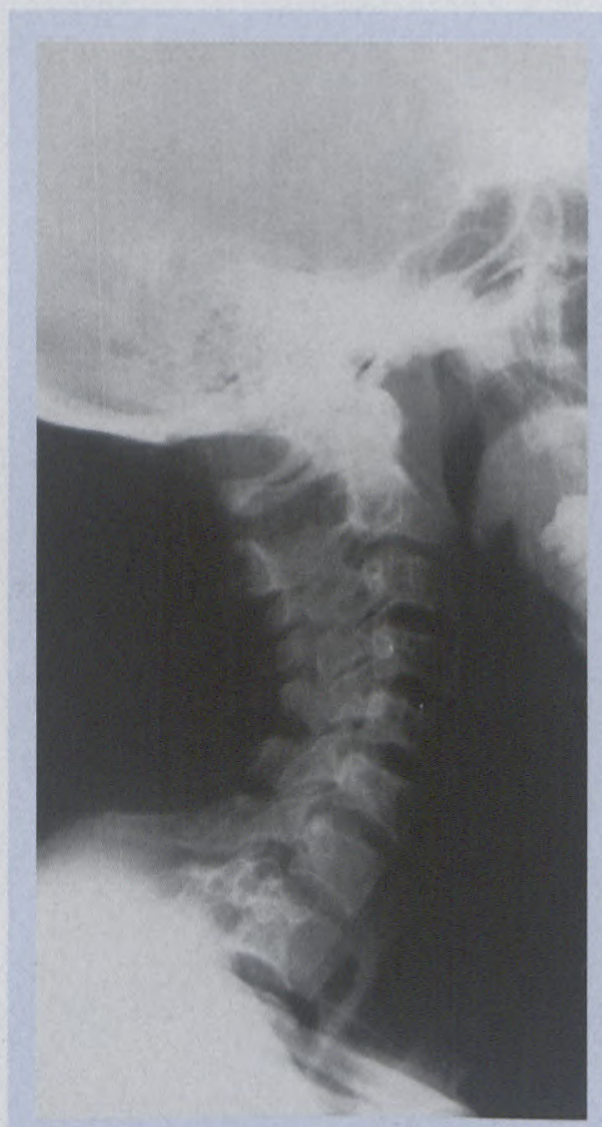

Fig. 1b. Lateral view of the cervical spine. The initial view showing suspected mandibular resorption. Spinous process of the 5th cervical vertebra resorbed.

showed only a residual dislocated condyle on the right side, and resorption of the condyle and coronoid process on the left side.

$\mathrm{X}$-rays of the hands (Fig. 6c) showed gross resorption of the terminal phalanges and dislocations. The feet showed less severe changes (Fig. 7).

A barium swallow (Fig. 5) was requested because the patient complained of difficulty in swallowing. This showed widening of the whole oesophagus with poor peristalsis and stasis. Reflux was demonstrated, the distal oesophagus was slightly narrower for a length of $8 \mathrm{~cm}$, with superficial ulceration, consistent with oesophagitis and early peptic stricture formation. 

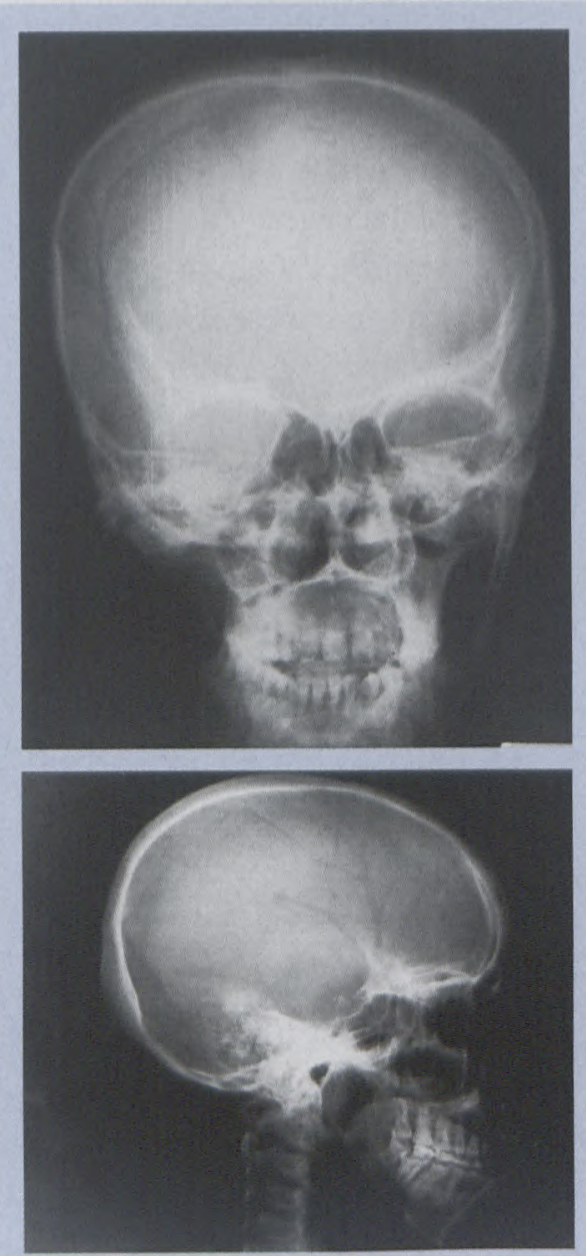

Figs. $2 a+b$. Skull views. Partial resorption of the right mandibular ramus. Floating residual condyle seen on the lateral view.

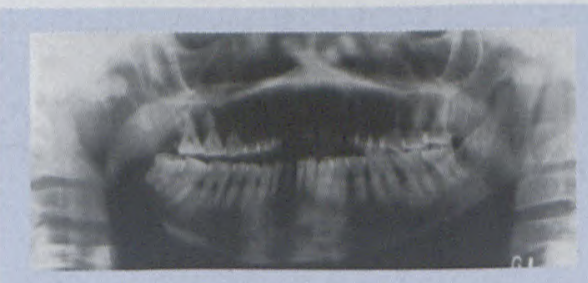

Fig. 3. Panorex view of mandible. Confirms resorption of the angle and ascending ramus of mandible, with residual condyle on the right side. Floating teeth noted at the $R$ mandibular angle. Resorption of the left condyle and coronoid process.

A follow-through examination was not done so the 'hide-bound' bowel sign and pseudo-diverticula could not be demonstrated.

At the time of the barium swallow the chest X-ray (Figs $4 a+b$ ) revealed destruction of the posterior 10th rib on the right side. There was also wavy

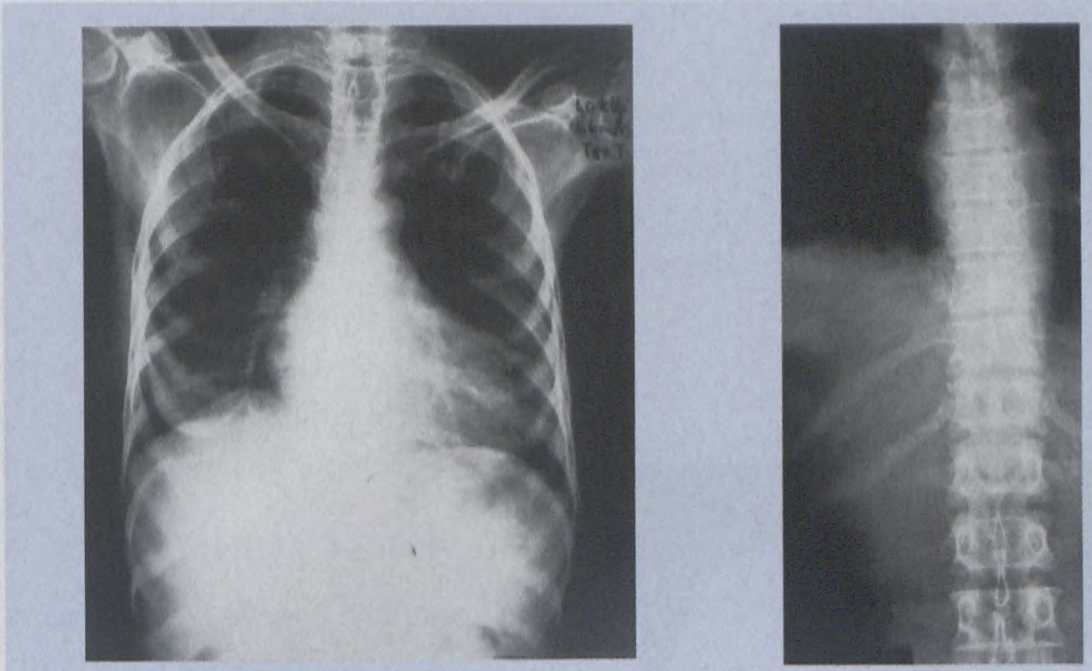

Figs $4 a+b$. Penetrated chest and lower rib views. Resorption of the posterior aspect of the right 10th rib. Wavy undulation of the right 11th and 12th ribs.

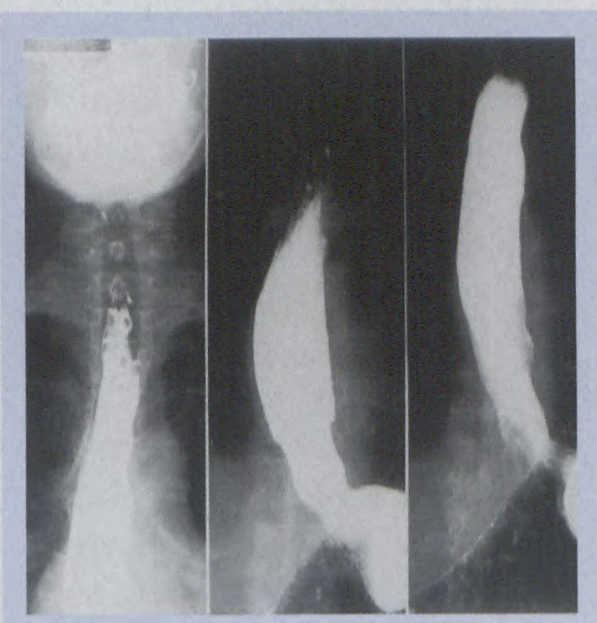

Fig. 5 Barium swallow showing dilated oesophagus with a peptic stricture of the distal part.

undulation of the 11th and 12th ribs on the right side. The lung fields appeared normal.

An HRCT scan of the chest showed no basal fibrosis or aspiration, but the oesophagus wall was thickened and a fluid level due to stasis was noted.

\section{Special investigations}

\section{Laboratory investigations}

Laboratory investigations revealed the following: $\mathrm{Hb}=8 \mathrm{~g} / \mathrm{dl}$ (iron defi-

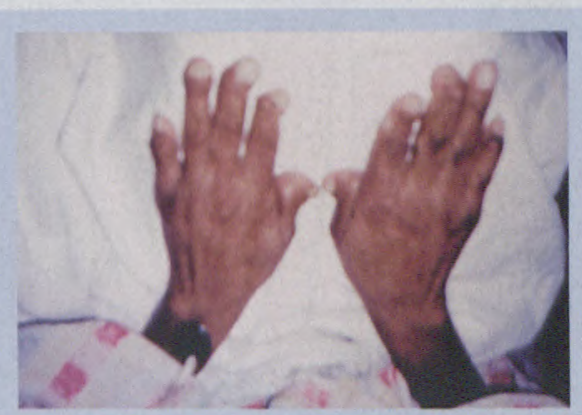

Fig. 6a. Photograph of the patient's hands.

ciency); (ii) extractable nuclear autoantibodies (negative); (iii) remaining blood tests also did not contribute to the diagnosis; (iv) the patient had proteinuria (U-total protein 213.0 (10.0 $140.0 \mathrm{mg} / \mathrm{L})$ ), but creatinine clearance was still within normal limits (92.6 with a range of $65-123$ units).

\section{Skin biopsy}

Biopsies were taken from both arms and the abdomen.

All the biopsies showed features of marked dermal fibrosis and sclerosis with minimal, mainly perivascular infiltrates of chronic inflammatory cells. Some of the adnexal structures appeared somewhat atrophic.

In the biopsy of the left arm (keloid-like plaque appearance) the 
connective tissue appeared somewhat more cellular.

In view of the clinical features of multi-organ involvement, the pathologist felt that the histological findings probably fitted best with systemic sclerosis.

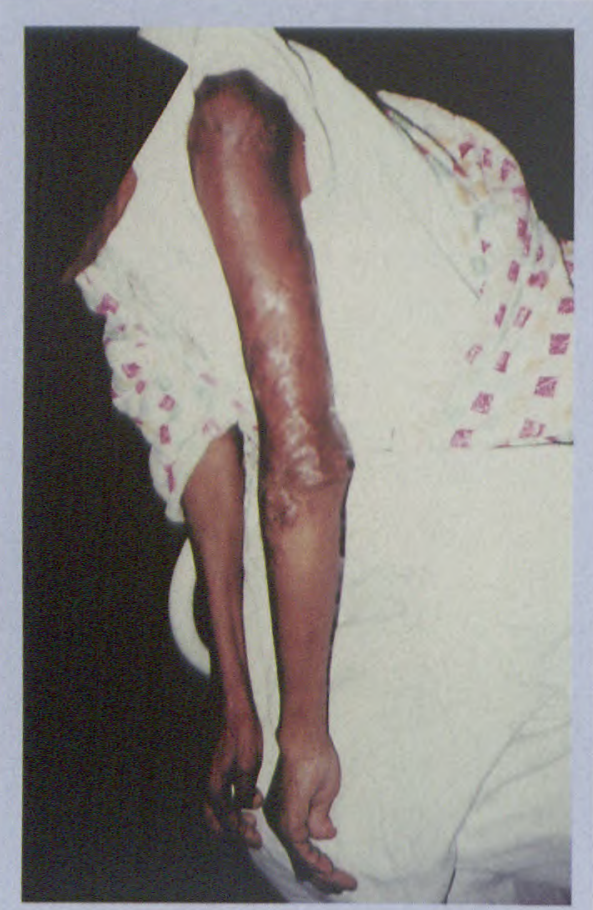

Fig. 6b. Photograph of the patients' arms demonstrating the skin thickening lesions.

\section{Gastroscopy}

- Grade II oesophagitis

- Hiatus hernia

- Antral gastritis.

\section{EMG}

- Showed signs of myopathy normal conduction, small motor units and polyphasic potentials

- Muscle biopsy was suggested.

\section{Discussion}

Progressive systemic sclerosis affects the 30 - 50-year age group with a 3:1 female-to-male predominance.

Clinically the patients have weakness and general debility with a $67 \%$ 5 -year survival rate.

Histologically there is vasculitis and submucosal fibrosis extending into muscles with smooth muscle atrophy. (Initially hypertrophy and finally atrophy of collagen fibres.)

This generalised disorder of connective tissue is characterised by inflammatory, fibrotic and degenerative changes, accompanied by vascular lesions on the skin, synovium, oesophagus, stomach, intestinal tract, heart, lung and kidney.

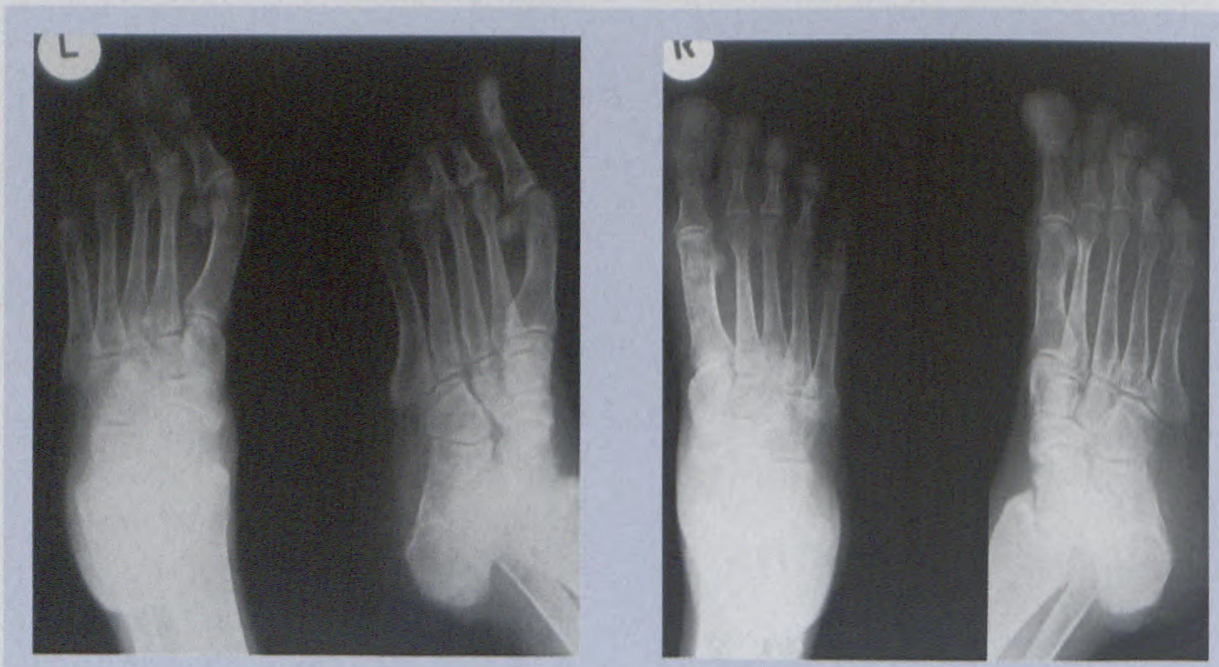

Fig. 7. Views of the feet showing resorption of the terminal phalanges. Subluxation of the 1st MP joint on the left side, with small erosions.
The initial complaint is usually Raynaud's phenomenon, swelling of the distal parts of the extremities or gradual thickening and tightening of the skin of the fingers.

Dystrophic calcification of soft tissues, which is not present in this case, usually occurs in the finger tips, and may develop over bony prominences.

The CREST syndrome may remain confined to the skin for long periods before involving the other systems.

The rheumatoid factor is positive in $35 \%$ of cases.

LE cells are present in 5\% and antinuclear factor antibodies are found in $30-80 \%$ of cases.

The reported incidence of systems involved is as follows:

\section{Musculo-skeletal}

- Arthralgia in $50-80 \%$ of cases

- Arthritis of IP joints of hands in $25 \%$ of cases

- Later flexion contractures may develop.

\section{Gastro-intestinal}

- $42-45 \%$ of cases

- Oesophagus affected in $42-92 \%$ of cases - this involves primarily the distal $2 / 3$ of the oesophagus, as the proximal $1 / 3$ consists of striated muscle

- Dysphagia $50 \%$

- Gastro-oesophaged reflux $70 \%$ with complications of stricture and Barrett metaplasia

- The stomach is less frequently involved

- Small bowel involved in $45 \%$ of cases

- Colon involved in $40-50 \%$ of cases

- Hypomobility and stasis in pseudodiverticula with bacterial over- 


\section{RADIOLOGY}

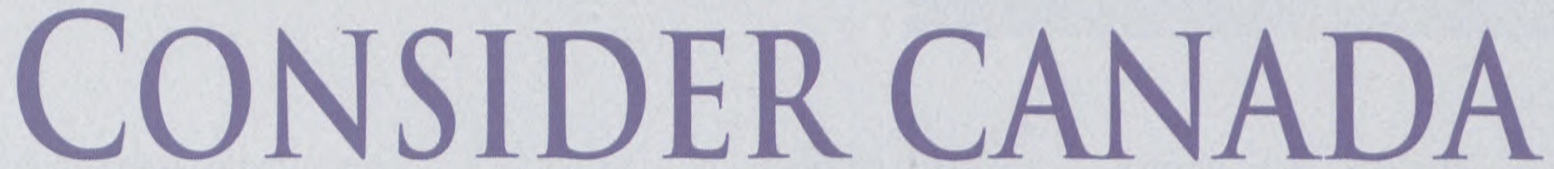

CONSIDER THE LIFESTYLE: Prince George and its region are surrounded by a network of trails for hiking, mountain biking or cross-country skiing, and just beyond are the mountains, rivers, and wilderness for virtually any activity. It is a safe and dynamic community with a true northern spirit. We have a wide range of cultural opportunities such as live theatre, a new art gallery, museum, a symphony orchestra, and many social, sports and community events during the year. We are also home to the University of Northern British Columbia.

CONSIDER THE OPPORTUNITY: The Northern Interior Health Region offers exciting opportunities to further your career in Radiology working in the Prince George Regional Hospital. In the

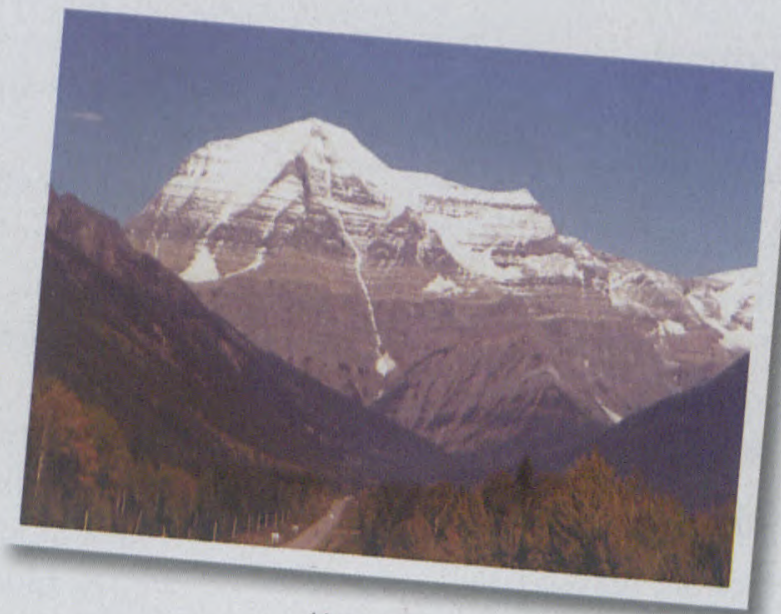

Mount Robson, British Columbia, Canada heart of Beautiful British Columbia, you can enjoy lifestyle options that are dazzling to even he most demanding individual.

CONSIDER THESE FACTS: The Prince George Regional Hospital is currently undergoing a $\$ 50$ million dollar building expansion to keep up with the demands of being a regional referral and trauma centre. The Radiology Department provides all imaging modalities including Nuclear Medicine. The hospital boasts leading edge technology including a Siemens Volume Zoom Multi-Detector CT, installation of a fixed 1.5T MRI, Digital Angiography \& Digital Fluoroscopy Suites, and a fully integrated Digital PACS system.

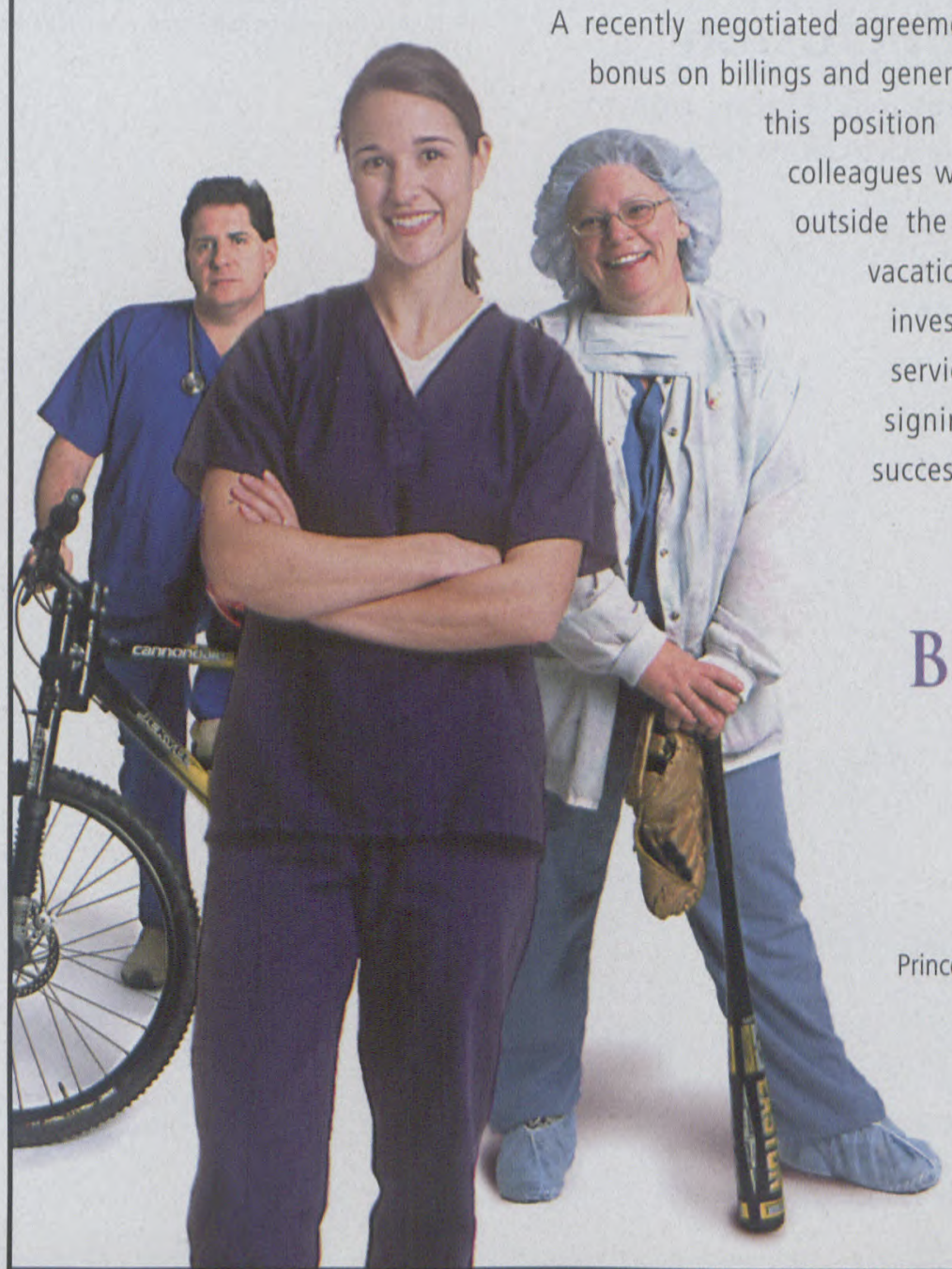

CONSIDER US...

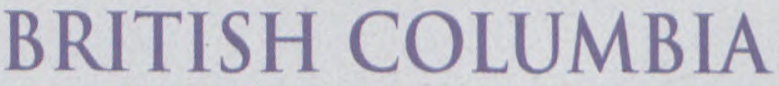
CANADA

NORTHERN INTERIOR HEALTH REGION

Prince George Vanderhoof Fort St. James Fraser Lake Burns Lake Granisle Mackenzie McBride Valemount

* For detailed information on career opportunities, please contact Colleen Stevens

\section{$1-250-565-2717$}

www.NIRHB.bc.ca or www.nmsbc.org 
growth interferes with normal absorption of fat.

\section{Pulmonary}

- $10-25 \%$ of cases

- Pulmonary fibrosis leads to pulmonary hypertension.

\section{Renal}

- $25 \%$ of cases involved

- Renal insufficiency is a major cause of death.

\section{Cardiac}

- Myocardial fibrosis

- Cardiac arrhythmias are often present.

\section{Radiological features of the skeletal system}

Initially there is thickening of the soft tissues of the fingers (Fig. 6a) but later the soft tissues become thin as the subcutaneous fat is replaced by fibrous tissue. There is tightening of the skin and flexion deformity of the fingers and other joints develops
(Fig. 6b). Calcinosis may develop.

Resorption of terminal tufts occurs and is progressive; distal, middle and proximal phalanges may be destroyed.

Other prominences of bone may be resorbed such as the medial aspect of the 5 th metacarpal base, outer margins of the radius and ulna, distal clavicle, acromion process, mandibular condyle, cervical spine and the superior margins of the posterior aspects of the midthoracic ribs.

Rib resorption is often bilaterally symmetrical and in rare cases may be profound. The cause of superior marginal rib resorption and mandible resorption in progressive systemic sclerosis is unknown but pressure atrophy resulting from skin thickening or osseous ischaemia may be responsible for mandibular resorption.

\section{Conclusion}

A 48-year-old African woman with known scleroderma is discussed demonstrating some of the less common skeletal manifestations, namely mandible and rib involvement. The more common soft-tissue calcifications were not present in spite of severe bony changes of the hands.

\section{References}

1. Dähnert W. Radiology Review Manual. 3rd ed. Baltimore: Williams and Wilkins, 1996: 624625 .

2. Grainger and Allison's Diagnostic Radiology. 3rd ed. Vol. 3 : Edinburgh: Churchill Livingstone, 1997: 1788.

3. Sutton D. ed. Textbook of Radiology and Imaging. Edinburgh: Churchill Livingstone, Vol. 1: 336-337, 487-489; Vol 2: 1399.

4. Pickhardt JJ. 'The hide-bound' bowel sign. Radiology 1999; 213: 837-838.

5. Moorhouse S. Gastro-intestinal scleroderma. S Afr Med J 1999; 89: 744.

6. Coggins Marc CA, Levine S, Kesack GD, Katzka DA. Wide-mouthed sacculations in the esophagus: a radiographic finding in scleroderma. Am J Roentgenol 2001; 176: 953954.

7. Gold RH, Bassett LW, Seeqer LL. The other arthritides. Radiol Clin North Am 1988; 26: 1208-1211.

8. Bassett LW, Blocha KLN, Furst DE, Clements $\mathrm{PJ}$, Gold RH. Skeletal findings in progressive systemic sclerosis (scleroderma). Am J Radiol 1981; 136: 1121-1126. 